\title{
El canto de lo material. Sobre El arte de narrar
}

\author{
Jorge Monteleone*
}

\begin{abstract}
Resumen
Juan José Saer publicó un único libro de poemas de nombre paradójico: El arte de narrar. Este trabajo analiza las razones estéticas que sustentan ese título en varios aspectos: la fusión de géneros literarios, habitual en la obra de Saer; el tema de la narración como un modo de otorgar sentido a lo real en la forma estética -el canto de lo material-, la sustitución del yo poético por el retrato del escritor y la persistencia de la voz lírica.
\end{abstract}

\section{Palabras clave}

Poesía. Arte de narrar. Yo poético.

\section{Narrar}

Uno de los enigmas irónicos que de inmediato abre el único libro de poemas de Juan José Saer es, precisamente, éste: "¿por qué, siendo un libro de poemas, se llama El arte de narrar?"1 Calificar el enigma de irónico podría ser banal. La ironía, que juega con la negación de la literalidad en este caso, es menos plausible que insuficiente, porque se agota en un juego ingenioso. La segunda posibilidad que abre es más cercana al universo de Saer, y se emparienta con la confusión de los géneros en la literatura -en especial esa tradición de la literatura argentina que siempre revindicó: una serie de obras singulares, atípicas, que no entran en ningún género preciso, como el Facundo de Sarmiento, las aguafuertes porteñas de Arlt, los poemas narrativos de Juan L. Ortiz, los relatos de Antonio Di Benedetto o los ensayos de Borges-. Esa

* Universidad de Buenos Aires - CONICET.

${ }^{1}$ La primera edición de El Arte de Narrar (1960/75) data de 1977 y fue publicada en la editorial Fundarte de Venezuela. En "Razones", que data de 1984, Saer anunciaba algunos proyectos, como la redacción de Glosa, que aparecería al año siguiente y afirmaba: "También sigo escribiendo poesía y estoy preparando una segunda edición de El Arte de Narrar, con cuarenta nuevos poemas" (Saer, 1986, p. 21). Esa segunda edición fue publicada en Santa Fe por la Universidad Nacional del Litoral en 1988, cuando en el Centro de Publicaciones se desempeñaban Hugo Gola, Edgardo Russo y Luis Novara. El nuevo volumen se compone ahora de tres secciones: la primera, "El Arte de Narrar 1960-1975" corresponde al libro de 1977. Los nuevos poemas restantes (cuarenta y cuatro) se reparten en las dos secciones siguientes: "Por escrito (1960-1972)" y "Noticias secretas (1976-1982)". En este ensayo nos referimos siempre al texto de la segunda edición, ampliada, de El Arte de Narrar, aunque tiene especial interés el conjunto de poemas que pertenecen a la primera, recopilados en la sección homónima. 
predilección es evidente en sus narraciones y poemas, por ello es atractivo conjeturar acerca de la elección de ese inusual, en apariencia contradictorio título para un volumen de poesía: El arte de narrar.

Saer declaró a menudo que su obra trataba de borrar las fronteras entre narración y poesía, combinando el rigor formal de la narración moderna con la percepción poética del mundo. Por mucho tiempo aspiró a escribir "una novela en verso" -deseo que autoparodió en su cuento "Recepción en Baker Street", de Lugar, donde Carlos Tomatis resume su proyecto de escribir en verso una nueva novela policial y narra el plausible argumento de un crimen resuelto en su vejez por Sherlock Holmes (Saer, 2000, p. 127-159)-. El lector habitual de sus textos admite con fruición la acentuada poeticidad de las narraciones, manifiesta en personajes que sostienen una mirada organizadora de un topos, es decir, un lugar conformado por un objeto o un conjunto de objetos que constituyen a la vez lo real y su deslizamiento hacia lo imaginario, por elusivo y borroso que sea. "La noción de objeto está en el centro de todo relato de ficción", escribió (Saer, 1999, p. 17). Ese sujeto suele alcanzar, por un breve instante, una atención desmesurada que no sólo parece sacarlo de una habitual distracción y sumergirlo por un breve lapso en la "permanencia de lo que fluye" o "el devenir", sino también obtiene en la ficción -es decir en el ámbito de lo imaginario- su sentido verdadero:

En lo continuo, en lo homogéneo, a pesar de la multiplicidad aparente, sigue estando todavía la punta de claridad mortecina -"yo"-, la fragilidad impensableque sin embargo dura y dura, en una especie de somnolencia turbia y monótona de la que a veces, sin ninguna razón, de un modo súbito, se despierta, para percibir, durante una fracción de segundo, la persistencia- de lo que fluye (...). (Saer, 1993, p. 148)

Ese particular estado psíquico suele cifrarse en un objeto, cuya descripción se demora y no produce un efecto de realismo sino un minucioso extrañamiento, donde la materia se manifiesta en supura presencia, como una intemperada totalidad. Se trata de esos instantes epifánicos de las narraciones de Saer, donde el tiempo parece coagularse en una súbita iluminación de lo real o, mejor dicho, en un pliegue del tiempo, un instante donde se precipita la mortalidad como una redención en la forma. Esto, que parece tan abstracto, es muy claro en las narraciones cuando se relata, literal y minuciosamente, esa experiencia de la objetividad del mundo en un hecho nimio, una cosa aislada, un suceso común. Ese efecto de poeticidad de la narración suele situar el objeto en el centro de lo ficticio y volverlo, en cierto sentido, ilimitado e intenso. Es habitual que esos objetos o las acciones que los involucran sean tan inolvidables como los personajes de la narración. A veces esa fusión con los objetos se centra en el simple acto de comerlos: el cordero asado de El limonero real (1974) o el salamín morosamente consumido de Nadie nada nunca (1980) -escena que Raúl Beceyro no puede omitir en su versión cinematográfica de la novela y que fascinaba a los poetas argentinos de los noventa en busca de un nuevo modo de mirar los objetos en el poema-. ${ }^{2} \mathrm{O}$ bien las mariposas que hipnóticamente se suspenden en el centro

${ }^{2}$ Uno de los miembros de esa generación de poetas, Fabián Casas, evocó: "En mis años mozos, mis amigos con los que hacía una revista de poesía comentaban admirados una y otra vez 
vacío del espacio abierto en ese mismo texto o se filtran en una superficie invisible del aire en la novela póstuma, La grande (2005).

En esa novela una mujer, Gabriela, cose un botón. El relato de ese acto mínimo se extiende a lo largo de tres o cuatro páginas y a medida que la escrupulosa descripción se revela en sus ínfimas peripecias y sus "catástrofes diminutas", se la magnifica hasta ocupar todo el espacio (Saer, 2005, p. 206-211). La maestría con la cual Saer relata los intentos de enhebrar el hilo, sus frustrados movimientos iniciales hasta que por fin el hilo atraviesa el ojo del hilo, provoca el mismo placer, a la vez físico y mental, que siente la protagonista antes de coser el botón a la suave tela de una blusa. Es probable que la percepción de ese objeto y el relato del hecho tengan la misma duración en el mundo real que en las páginas del texto, de tal modo que la ficción crea un doble y paradójico extrañamiento. Por un lado, esa morosa detención de la peripecia, donde el texto se adensa, permite percibir lo que podríamos llamar la materialidad significante de la ficción, liberada de toda ilusión mimética, para constituirse como absoluto artificio de lenguaje. Por otro lado, permite desnaturalizar la ignorante costumbre del vivir en su veleidosa distracción, olvidada de sí al paso del tiempo, para sentir en todo su despliegue el devenir, como si el tiempo mismo también se materializara. Surge así ese instante epifánico donde el objeto posee una presencia absoluta, es decir, cuando literalmente aparece. $Y$ en esto reside la poeticidad del relato de Saer, a partir de la narración del objeto con la intensidad de percepción atenta, del mismo modo en que un poema indaga la representación de un instante consagrado en la experiencia de las cosas. El sitio donde esos objetos alcanzan su completa manifestación es en la forma literaria. Este retorno a la objetividad del mundo opone las cosas imaginadas a una conciencia oscurecida. A esto Saer lo llama, con una sencillez principista, narrar: "La narración -escribió- es un modo de relación del hombre con el mundo. Toda novela es narración, pero no toda narración es novela" (Saer, 1986, p. 19).

Por ello El arte de narrar es un título que quiere parecer irónico, cuando en verdad trata de un tema esencial: el motivo de los poemas de Saer es ese complejo arte extraordinario y antiguo que consiste en narrar, narrar el tiempo, narrar las cosas, narrar interminable, ilimitadamente, el puro acontecer del mundo exterior, que va de la extrañeza a la plenitud.

\section{Ritmo}

Los poemas más característicos del libro, por su número y su originalidad, son aquellos donde se cruzan poesía y narración: podrían leerse como breves relatos, aunque tienen la dimensión rítmica del verso no sólo por su disposición en la página, sino también por la peculiar sintaxis de Saer. Con la excepción de un soneto en el segundo poema de la serie "Quevedo" ("Relox de sol"), en los versos de El arte de narrar está por completo ausente la prosodia, siquiera parcial, de la métrica española,

cómo un hombre cortaba un salamín en el comienzo de una novela de Juan José Saer que se llamaba Nadie nada nunca. Perdón, me corrijo: lo que contaban era cómo un escritor había escrito de manera intensa y precisa hasta la exasperación a un hombre cortando un salamín" (Casas, 2007). 
o cualquier otro recurso rítmico cuyo patrón sea iterativo -ni rimas, ni aliteraciones, ni homofonías, ni juegos significantes-. El ritmo del verso de Saer guarda estrecha relación con esa sintaxis que también puede hallarse en pasajes de su prosa: por ejemplo en ese modo de situar al final de la frase el objeto directo o la acción principal, creando una expectativa a través de incisos, de subordinaciones, de complementos, donde lo afirmativo se carga de dubitación. Como si el despliegue de lo real fuera creado por ese hábito de la somnolencia que busca con rodeos una frase, cuya directa expresión se le escapa, pero cuya fuerza expresiva reside en su escansión peculiar:

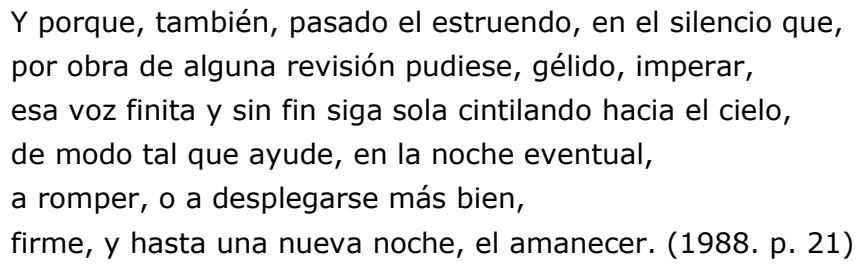

Pero la mención de la somnolencia no es decorativa y responde a una de las claves por las cuales poesía y narración forman igualmente para Saer manifestaciones de un "arte de narrar" como suprema facultad de una poiesis de lo imaginario. En un texto que bien podría tomarse como un manifiesto, "Narrathon", Saer sostiene que narrar no es sólo una operación de la inteligencia, sino del cuerpo entero y que "el medio natural de la narración es la somnolencia" (Saer, 1997, p. 155). Este carácter está lejos de significar una disminución de las facultades intelectivas y creadoras. Se trata del abandono de las convenciones y retóricas de sentidos prefijados que la razón suele poner en juego, para hallar en la escritura lo imprevisto -aquello que no está gobernado por la doxa- e imponer un orden de sentido nuevo y particular. Aunque posea a primera vista un parentesco con el programa surrealista -"hay cierto arrojo de la mente que únicamente el sueño, en su abandono, puede aportar", escribe (1997, p. 156)-, no se trata de un irracionalismo, sino de un método. En él, gobernado por esta semivigilia, hay una serie de tabúes que el escritor debería evitar para no dar pasos en falso y caer en facilidades retóricas o en lo inauténtico: "Esa fuerza tensa, acerada, de rechazo, ha de ser, preferentemente, continua, para que quede, entre el acto de narrar y la historia, una franja aunque, lo repito, metafórica, de nada" (1997, p. 156).

Pero acaso lo más relevante sea que la narración es un acto físico o, mejor dicho, un acto que involucra en el narrar esa dimensión que está más allá del discurso y corresponde a lo rítmico, cuyo fundamento último es corporal -como oblicuamente lo reconoce Saer al citar a Henry James en inglés, hablando del extraño e irregular ritmo de la vida:

El medio natural de la narración es la somnolencia. En ese río espeso, la inteligencia, la razón, se abren a duras penas un camino, siempre fragmentario, tortuoso, arduo, entre las olas confusas de lo que James llamó the strange irregular rhythm of life. [...] La somnolencia, lejos de atentar contra la ilación, o contra el orden, impone, más bien, un orden propio, una ilación de la que cambia, únicamente, en relación con la ilación lógica, la dimensión en la que se constituye. (1997, p. 155-156) 
Con una poderosa intuición, Saer ha liberado el ritmo de los avatares de la métrica y los ha situado en su exacto lugar: en su cruce entre el sentido y el sujeto. Por ello, la busca de la somnolencia en el narrar es de hecho la particular búsqueda de un ritmo que, como aseguró Meschonnic, "es el sentido de lo imprevisible" (2007, p. 94). De allí entonces que El arte de narrar consista en dar respuesta a una apelación o un llamado de lo real hacia donde la escritura misma se dirige, una disposición heurística cuyo resultado es aleatorio respecto del sentido. O bien lidia con un sin sentido en la mudez de lo concreto para dotarlo de una significación vacilante, es decir, no anclada en la fijeza de una verdad universal. Y aquí es el punto en el cual El arte de narrar se torna una poiesis de lo imaginario. Mientras un lugar común indica que narrar es contar una historia, para Saer, la narración es hacer cantar lo material. Al hablar de lo material no indica la materia sino "cualquier objeto o presencia del mundo, físico o no, desembarazado de signo" (Saer, 1997, p. 175). Este canto del mundo no es una atestiguación de lo dado, sino una invención que, en la medida en que es imaginaria, no elimina el mundo, sino que establece con éste una relación recíproca. Narrar "no consiste en copiar lo real" sino en brindarle una "coherencia nueva" en la determinación de la forma literaria. Así entonces se constata la objetividad del mundo, mediante un canto de lo material, que consiste en la creación de sentido de un acto de narrar como un acto esencialmente poético. Por eso mismo, la división genérica entre narrar y poetizar para Saer carecería por completo de relevancia.

\section{Retratos del yo}

El libro está dividido en tres secciones, pero aquellos poemas más característicos donde se reúnen poesía y narración forman parte en su mayoría de la primera, que da el nombre al libro. Para ello Saer suele utilizar figuras de escritores que se introducen mediante un relato. En un apartado del texto "Razones" [reproducido en este dossier], escrito a instancias de María Teresa Gramuglio para la compilación Juan José Saer por Juan José Saer, mencionaba su preferencia por utilizar "personajes escritores", o próximos a la actividad literaria. La explicaba por tres motivos: porque brinda apoyo empírico a un sistema de representación realista; porque incluye personajes que expresan la visión íntima del autor $y$, de ese modo, el observador puede ser incluido en lo observado; y, en fin, porque ante la crisis de la representación interesan menos las historias que los medios utilizados para hacerlo (Saer, 1986, p.21). Muchas veces el uso de la primera persona corresponde al enunciado de uno de estos personajes. Hay, además de estas figuras "biográficas", otras que son explícitamente ficcionales, aunque comparten el mismo estatuto: por ejemplo el Dr. Watson, Don Giovanni, Robinson Crusoe, Juan Moreira o Pichón Garay e Higinio Gómez -personajes de narraciones de Saer-. Al evocar estas figuras, Saer ejercita una cierta disolución del nombre del autor y una pareja reducción de lo contingente, a favor de dos o tres hechos que simbolizan rasgos de la figura representada. En cierto modo, en el cuento "Recepción en Baker Street", Tomatis imagina la presentación de los "personajes míticos" -como Sherlock Holmes- en su novela en verso, y asegura que no hay que presentarlos mediante detalles psicológicos de su personalidad verdadera, sino en "un orden protocolar de rasgos cristalizados que permitan reconocerlo de inmediato" 
(Saer, 2000, p. 140). Algo de esa técnica se reconoce en los retratos literarios de los poemas. Es indudable que debe contarse con la complicidad, selectiva, de un lector que pueda interpretar los guiños para que esas figuras se comprendan en toda su dimensión. En algunos casos el nombre se explicita: Petrus Borel, Dylan Thomas, Quevedo, Dante, Sartre o Rubén (Darío); en otros pueden identificarse poemas que, sin mencionar sus nombres, tratan sobre Dostoievsky, Faulkner, Joyce, SacherMasoch, Mozart, De Quincey, Aldo Oliva, Shakespeare o Pessoa. Su construcción, no obstante, puede ser rastreada en fuentes diversas y relativamente accesibles, que el autor manejó, pero que casi nunca son explícitas. "El discípulo de Crates" se refiere a los filósofos cínicos, en particular a Metrocles y las alusiones, además del texto canónico de Diógenes Laercio, corresponden al cuento "Crates, cínico" de Marcel Schwob en Vidas imaginarias. El título "Oxford, Mississippi, (Blotner, II, 1401)" alude a la ciudad de Faulkner y a una cita de la monumental biografía canónica sobre el escritor de Joseph Blotner. "Bottom's dream" es el sueño de Bottom, en Sueño de una noche de verano, de Shakespeare. "Ann" es aquella Ann de la Oxford Street, la prostituta que Thomas de Quincey buscaba en Londres, como refiere Confesiones de un opiómano inglés. "Recuerdos del doctor Watson" alude a la primera novela de Sherlock Holmes, Estudio en escarlata. Curiosamente, la frase de Holmes "Esta tarde en el Concert Hall oiremos cantar a Norman Neruda" es un error de Saer, ya que, en la novela de Conan Doyle, Norman Neruda no es un hombre, sino una mujer llamada Wilma Norman-Neruda, y no era cantante, sino una célebre violinista de la época que Holmes, aficionado al violín, admiraba.

En todos estos casos el nombre del autor se omite, tal como ocurre en He weeps over Jim. Es uno de los textos en primera persona donde un personaje no toma el lugar del yo, sino que el sujeto que "llora por Jim" manifiesta su elegía y su deuda con el escritor irlandés. El poema está pleno de claves, en parte tomadas de otra biografía canónica: James Joyce de Richard Ellman, publicado en 1959 y revisado en 1982. El conocimiento de estos presupuestos nada agrega a la eficacia lírica del poema, pero lo perfecciona. La mención de "Carlos, el cordero" alude a Charles Lamb. En unos pocos versos se acumulan luego referencias algo herméticas que corresponden a precisos momentos de la vida de Joyce. Es decir, vemos la reunión de unos pocos rasgos cristalizados para dar cuenta de una personalidad -como se proponía Tomatis- cuando el yo enumera recuerdos, "momentos", que pertenecen al autor venerado:

Una humildad por lo menos me has enseñado, la de buscar algo eterno fuera de mí: el momento en que atravesabas los puentes de Trieste en compañía de Svevo, los momentos en que tu mano, ardua, escribía What are

Dublin and Galway compares with our memories,

o alguna otra permanencia concerniente a tu persona,

las florcitas indestructibles de Quinet sobreviviendo al hundimiento

de los imperios

El momento de la fotografía de C. P. Curran

(I was wondering would be lend me five shillings...)

con las macetas y una de las dos hojas del ventanal abierta atrás [...] (Saer, 1988, p. 36-37) 
Estos recuerdos aluden a hechos muy precisos de la vida de Joyce que se evocan. Por ejemplo, el momento en el que se encuentra con Italo Svevo en Trieste. Por entonces, el 12 de julio de 1912, le escribe a Nora Barnacle y le reprocha que en sus cartas no mencione ninguno de los lugares de Dublín en los que se encontraron y que guardan "tantos recuerdos de nosotros". La carta finaliza con la cita del poema de Saer: "¿qué son Dublín y Galway comparados con nuestros recuerdos?". Las "florcitas indestructibles de Quinet" aluden a una frase del botánico que menciona las flores que siguen naciendo, mientras a su alrededor las ciudades cambiaron sus nombres y sus amos, se hundieron y derrumbaron y desaparecieron en la nada. Esa alusión aparecería sobreentendida en una frase del Finnegans Wake (II, 3). La fotografía tomada por su amigo C. P. Curran en 1904 es muy conocida y presenta a Joyce como un arrogante joven irlandés que mira desafiante a la cámara, con las manos en los bolsillos, una gorra blanca y las piernas abiertas frente a un invernadero -"con las macetas y una de las dos hojas del ventanal abierta atrás"-. Cuenta Curran que al preguntarle a Joyce en qué estaba pensando al fotografiarlo, el escritor respondió la frase citada por Saer en inglés: "me preguntaba si me prestarías cinco chelines..."

La función de esa preferencia general de la literatura de Saer, corresponde en su poesía a la sustitución del sujeto lírico por el retrato de estas figuras, y en consecuencia al alcance de cierta impersonalidad por interpósita persona, la máscara de los escritores, sin renunciar no obstante a una inflexión subjetiva. Esta elección obedece a un rasgo más general, que anotó Julio Premat: para Saer, la imagen de escritor -tanto la propia como la ajena- se caracteriza paradójicamente por "un rechazo explícito de definir imagen alguna", que se apoyaría en una inclinación drástica que no sólo elude prolijamente cualquier atisbo autobiográfico, sino también, en sus ensayos sobre otros escritores, reproduce "el mismo vacío de identidad, de personalidad e inclusive de voluntad" (Premat, 2002, p. 282, 293). Saer ha declarado que "el escritor no es nada, nadie" y si para el resto de los hombres esa ausencia de contenido es llenada con imágenes sociales, "para el escritor todo el asunto consiste en preservarla" de ellas (Saer 1997, p. 19). Cabe agregar que habría dos modelos de este carácter. El primero corresponde a una antigua idea borgeana, que desde culto a la nadería de la personalidad en los años veinte, arribó a su conocido retrato de Shakespeare en la prosa "Everything and nothing" de El hacedor (Borges, 1960), según la cual el autor es un vacío poblado exclusivamente por sus personajes y a su vez el modelo de la divinidad, que es "muchos" en el universo de sus criaturas y "nadie" en sí mismo. La prosa de Borges comienza de un modo afín a la declaración de Saer: "Nadie hubo en él". El otro modelo es Juan L. Ortiz, un hombre que deliberadamente escamoteó su biografía. "Soy un hombre sin biografía en el sentido en que generalmente ésta se considera", escribió. Sus "Notas autobiográficas" ocupan apenas una página y media de sus Obra completa (Ortiz, 1996). Ese vacío de identidad es el antecedente ostensible para la concepción de Saer: en Juanele la biografía no existe porque se transformó en mito poético (Monteleone, 2004). El retrato ocupa ese lugar en la poesía de Saer. Levanta una imagen del personaje escritor, que a su vez sustituye el yo lírico, cuando la condición fundante de ese retrato es un previo vacío: el escritor como "nada, nadie". 


\section{Poéticas}

Hay tres poemas del libro que se llaman "El arte de narrar" y obrarían como "artes poéticas". El primer poema con ese título es el segundo del libro y sin duda su posición es estratégica. El volumen se inicia con el poema "De L'art romantique", para aludir a la colección de ensayos de Charles Baudelaire publicado en 1869 donde convencionalmente se incluye la serie "Réflexions sur quelques-uns de mes contemporains". El retrato $V$ corresponde a Petrus Borel, conocido como el lobo o el licántropo. Los surrealistas lo salvarían del olvido, pero en el texto de Baudelaire se trata de una figura algo oscura y tributaria del fracaso: "siempre tuve simpatía por este infeliz escritor, cuyo genio malogrado, pleno de ambición y de torpeza, sólo supo producir fracasos minuciosos, borrascosos relámpagos, figuras con algo de bizarro, [...] sólo tuvo el encanto de la voluntad iy eso ya es bastante!" (Baudelaire, 1980, p. 524). Por ello en su poema Saer escribe: "Aprendamos, / en esta hora, de Petrus Borel, / [...] / aunque se haya, por fin, oscuro, hundido en el cielo, / y ninguna estrella lleve su nombre" (p. 7). Recupera, desde Baudelaire, la voluntad y la pasión, "el amor por la palabra, la lealtad suicida a los lobos", aun a costa de la desaparición. Borel es la primera figura que encarna al poeta y su carácter disminuido es el que elige Saer para vindicar la poiesis desde el fracaso.

En la página siguiente aparece entonces el primer poema de la serie de tres que lleva el nombre "El arte de narrar", que comienza: "Ahora escucho una voz que no es más que recuerdo" (p. 8). En el poema se habla del modo en el cual la conciencia -que es una conciencia literaria y no sólo alude al escritor, sino también al lector- se abre en el paso del recuerdo, es decir, al momento en que el recuerdo es proferido como lenguaje: el ojo recorre en la hoja blanca la "red negra" de los signos. El recuerdo aparece como un rumor que resuena, palpita en el oído y luego hiere el corazón. Ese momento en el cual el recuerdo de algún modo se materializa es uno de los artificios del devenir, uno de los sostenes de la duración, sobre los que tanto escribió Saer y que obra aquí como la posibilidad de rescatar un instante y fundar en él una cierta redención del tiempo, esa "lluvia verde que se abre imposible hacia un árbol glorioso". Pero el poema que sigue parece un comentario o una nota al pie de éste: "Recuerdos del doctor Watson". Y en él se abre otro recurso: el paso de los recuerdos a la escritura. El hecho incontestable de que estos recuerdos pueden ser recuerdos falsos. Aquellos recuerdos "parasitarios" que aparecen en Glosa: recuerdos de experiencias ajenas que no por eso pierden cohesión y sentido. Un conjunto de imágenes vinculadas a recuerdos inexistentes que sin embargo tienen fuerza ficcional, como los recuerdos de un personaje, que pueden tener más "realidad" que los reales y dejar huellas profundas en la memoria. $Y$ en ese caso los "hombres del porvernir, plagados de irrealidad" jamás tendrán ese "collar de sólidos minutos" que Watson ya poseía en el reino inalterable de la ficción (p. 9).

El paso del recuerdo a la escritura no siempre corresponde a un recuerdo existente. Esto responde a un fenómeno global que Piglia observó: en el centro de la narrativa contemporánea, desde Borges a Philip K. Dick asistimos a la destrucción del recuerdo personal, no hay memoria propia ni recuerdo verdadero $y$, en consecuencia, se diluyen la identidad personal y el pasado reconocible. Narrativamente, afirma Piglia, "podríamos hablar de la muerte de Proust" (Piglia, 1999, p. 63). Esa irrisión de la 
memoria involuntaria como fuente del relato aparece explícitamente en Saer desde "La mayor" y "A medio borrar" (Saer, 1976), como lo advirtió la crítica. ${ }^{3}$ Por esa razón, como antes vimos, Saer sustituye el yo lírico por el retrato biográfico, que a la vez se astilla en fragmentos y revela un vacío de origen.

En el segundo poema "El arte de narrar" se habla entonces de los libros que almacenan "recuerdos falsos para memorias verdaderas". Ante la falsedad del recuerdo que pasa a la voz, ésta se encarna en signos que construyen otro objeto, imaginario, más persistente que el real: la "rosa de lo narrado". En ella confluyen, entonces, los objetos y el acto de narrar:

flor de niebla, olvido hecho de recuerdos retrógrados

rosa real de lo narrado

que a la rosa gentil de los jardines del tiempo

disemina

y devora.

(Saer, 1998, p. 75)

Aquí reaparece la rosa de Milton, según Borges, que es pensada como una "cosa más agregada al mundo". El libro del poema de Saer, concebido como una explosión que enceguece y horada los ojos del escritor y del lector, se transforma en una rosa concentrada de luz, una rosa que persistirá siendo ajena y más duradera que la desdicha que pudo engendrarla.

El tercer poema "El arte de narrar" dice:

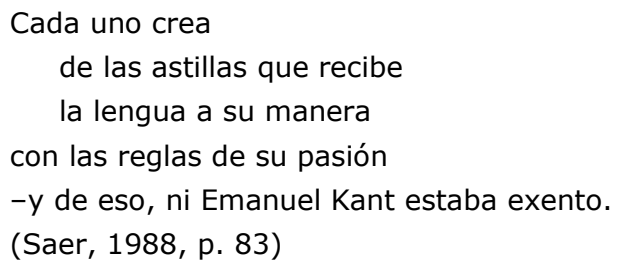

Aquí aparece uno de los motivos centrales de la literatura de Saer y es el vínculo entre la experiencia vivida y la posibilidad de su relato en el lenguaje -lo cual es otro modo de narrar el devenir. $Y$ aquello que obra como el código transfigurador y transubstanciador, es la pasión -incluyendo la irremediable ironía sobre Kant, que procuró construir una moral racional que no se basara en la naturaleza humana-. La pasión impone sus reglas y con ellas, de algún modo, lo que estaba destinado a esterilizarse, obtiene un simulacro de vida. Reaparece aquí la justificación del fracaso de Petrus Borel, su voluntad literaria sostenida exclusivamente en la pasión. También en el poema "Aldo", cuya evidente figura es el poeta rosarino Aldo Oliva, se lee que "al hablar todo lo que le queda de pasión se concentra" (p.15) y aun su élan poético es algo más que la pasión misma: lo manifiesto de esa apelación, de esas señales, de ese llamamiento que se hace desde un lugar incierto para que el acto de narrar se configure.

\footnotetext{
3 "En este sentido, la poética de Juan José Saer viene a discutir el proyecto de En busca del tiempo perdido de Marcel Proust, fundado en la posibilidad de narrar a partir de la memoria que sobreviene azarosa pero efectivamente" (Dalmaroni y Merbilhaá, 2000, p. 331).
} 
En estos tres poemas, ya sea mediante el paso del recuerdo (falso) a la voz, de la voz al signo en la escritura, y de ésta a la existencia, en un retorno del lenguaje a la vida sostenido por la pasión, El arte de narrar plantea el problema de la existencia de un yo cuando de hecho el sujeto real se ausenta y en su vacío sólo resta esa única voz fantasmal o, para decirlo con el retrato del escritor, "una nada". ¿Qué queda al fin del yo en su canción de lo material? ¿Qué yo o que huella del yo persiste en ese acto del narrar?

Esa cuestión parece respondida en uno de los poemas más largos del libro, "Diálogo bajo un carro", donde conversan José Hernández y su hermano Rafael, que remonta a un libro en el que Saer ve el paradigma de la confusión genérica entre poesía y narración, el Martín Fierro (Saer, 1988, p. 28, 32). En su ensayo "Martín Fierro: problemas de género", aquello que Saer exalta del poema de Hernández es su atipicidad genérica y habla de un modo lírico-narrativo del poema. "Lo que Borges llama 'el accidente del verso' es la disidencia fundamental, irreductible, del Martín Fierro, con cualquier novela del siglo XIX", escribe (Saer, 1997, p. 64). El verso es para Saer el elemento rítmico organizador y generador donde verso, relato y canto se reúnen. Pero ese elemento rítmico, no ocurre sólo en la estructura versal, sino también en la enunciación, en la representación imaginaria de una voz. Por un lado, debido a su carácter acentuadamente lírico -y ahora diríamos, monológico- donde, detrás de la voz del gaucho extrovertido se disimula su autor. Por otro lado, por el carácter dramático -es decir, teatral- de los monólogos. Es decir, Saer acuerda con la idea de Martínez Estrada sobre Martín Fierro: no es un poema épico (como afirmaba Lugones) ni una preforma de la novela (como sostenía Borges), sino un poema lírico. Y el aspecto lírico remite a la articulación de una voz en el poema, una voz equidistante entre lo personal y lo impersonal, entre la capacidad de nombrar y la nada.

En el poema "Diálogo bajo un carro", después del asado, los dos hermanos hablan tendidos en la hierba. Imaginemos esas dos voces que van apagándose en el relente del sol, mientras mueren las brasas. Los años pasan para ellos y la violencia del país los vuelve convictos de sus propios sueños. De pronto, José Hernández distingue otra voz, la voz de los árboles, que hablan un lenguaje apenas audible y que no tiene traducción. O la voz del verano, que habla para sí misma. Rafael, en cambio, no las oye, o apenas oye el murmullo del siglo ensordecedor, la historia que rechina rumorosa. Esas voces -le dice Rafael a su hermano José Hernández- te salvarán. "Se salvará la voz / no el que la escucha", le responde. Y aunque algo se edifique de este horror vivido -le explica- el precio será tan alto que los sueños mismos serán condenados. Esta parábola poética alude a una voz que desaparece en el yo mortal y a otra, ficcional, que persiste, desdoblada en el aire del mundo y en el lenguaje de la literatura. A partir del último libro de Saer, se comprende que toda literatura es póstuma. ${ }^{4}$ Todo escritor debe escribir como si fuese una nada o, como quería Kafka, como si fuese un muerto.

\footnotetext{
${ }^{4}$ La novela La grande es, a la vez, una novela inconclusa y una novela póstuma. Este contenido paradójico permite explorar el último texto de Saer en un vínculo cierto con la existencia: en él hay una constante reflexión y una apuesta estética sobre el sentido del devenir, que obliga a ser leído en este contexto particular como un significado suplementario $-y$, tratándose de Saer, nunca sentimental sino irónico- a la idea de la muerte del autor. Lo póstumo sería así la condición temporal de aquello que se presenta como acontecer de la finitud en el seno de la literatura. Estudiamos este aspecto en: Monteleone, 2006.
} 


\section{Bibliografía}

BAUDELAIRE, Charles. Oeuvres complètes. Edición de Michel Jamet. Paris: Laffont, 1980.

BORGES, Jorge Luis. El hacedor. Buenos Aires: Emecé, 1960.

CASAS, Fabián. "El enfrentamiento a algo superior", Página / 12. Buenos Aires: 13 de junio de 2007.

DALMARONI, Daniel; MERBILHAÁ, Margarita. "'Un azar convertido en don'. Juan José Saer y el relato de la percepción". En JITRIK, Noé. Historia crítica de la literatura argentina. Tomo 11: DRUCAROFF, Elsa (Directora del volumen). La narración gana la partida. Buenos Aires: Emecé, 2000, p. 321, 343.

MESCHONNIC, Henri. La poética como crítica del sentido. Buenos Aires: Mármol / Izquierdo Editores, 2007.

MONTELEONE, Jorge. "Juan L. Ortiz: el hombre sin biografía". Lucera, 7. Rosario: Centro Cultural Parque de España, primavera 2004, p. 74, 79.

"Lo póstumo: Juan José Saer y La grande". Ínsula. Revista de letras y ciencias humanas, 711 (número dedicado a las letras argentinas), Madrid: marzo 2006, p.14, 17

ORTIZ, Juan L. Obra Completa. Edición de Sergio Delgado. Santa Fe: Universidad Nacional del Litoral, 1996.

PIGLIA, Ricardo. Formas breves. Buenos Aires: Temas, 1999.

PREMAT, Julio. La dicha de Saturno. Escritura y melancolía en la obra de Juan José Saer. Rosario: Beatriz Viterbo, 2002.

SAER, Juan José. El limonero real. Barcelona: Planeta, 1974.

. La mayor. Barcelona: Planeta, 1976.

. Nadie nada nunca. México: Siglo XXI, 1980.

. Juan José Saer por Juan José Saer. Buenos Aires: Celtia, 1986.

El arte de narrar. Santa Fe: Universidad Nacional del Litoral, 1988.

. Lo imborrable. Buenos Aires: Alianza, 1993.

El concepto de ficción. Buenos Aires: Ariel, 1997.

. La narración-objeto. Buenos Aires: Seix Barral, 1999.

Lugar. Buenos Aires: Seix Barral, 2000.

. La grande. Buenos Aires: Seix Barral, 2005. 


\section{Abstract}

Juan José Saer has wrote one single book of poetry which title is paradoxical: El arte de narrar (The art of narration). This work analyzes the aesthetics reasons for the election of that title: the usual mixing of literary genres in Saer's works; the narration theme to bring meaning to reality by the literary form -the "material canto"-, the substitution of poetic self by a writer's image and the persistence of the lyrical voice.

\section{Keywords}

Poetry. Art of narration. Poetic self. 